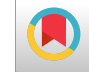

\title{
Investigation of Total Phenolic Content of Tilia dasystyla and Polygonatum orientale Desf Extracts and Their Cytotoxic Effect on the Osteogenic Sarcoma (Saos-2) Cancer Cell Line
}

\author{
Roshanak Zarringhalami (ii) ${ }^{1}$, Parichehr Hanachi (iD ${ }^{1,}$, , Ertuğrul Kaya (iD ${ }^{2}$, Aydan Fulden Ağan (iD ${ }^{3,4}$, \\ Kağan Ağan (iD ${ }^{3,5}$ and Mert Donmez (iD ${ }^{6}$
}

${ }^{1}$ Department of Biotechnology, Faculty of Biological Science, Alzahra University, Tehran,Iran

${ }^{2}$ Medical Pharmacology, Faculty of Medicine, Duzce University, Düzce, Turke

${ }^{3}$ Experimental Animals Application and Research Center, Duzce University, Düzce, Turkey

${ }^{4}$ Biotechnology Institute, Ankara University, Ankara, Turkey

${ }^{5}$ Medical Physiology, Faculty of Medicine, Duzce University, Düzce, Turkey

${ }^{6}$ Duzce University, Düzce, Turkey

"Corresponding author: Department of Biotechnology, Faculty of Biological Science, Alzahra University, Tehran, Iran. Email: p.hanachi@alzahra.ac.ir

Received 2019 May 20; Revised 2019 December 08; Accepted 2019 December 17.

\begin{abstract}
Background: Osteosarcoma; is one of the most common malignant tumors. Nowadays, because of the many side effects of cancer drugs, the usage of herbal medicine which can inhibit or eliminate cancer cells by their antioxidant compounds is increased.

Objectives: In the present study anticancer effect of Tilia dasystyla and Polygonatum orientale Desf different extracts on osteogenic sarcoma (Saos-2) cancer cell line was investigated and their polyphenolic compounds were identified by liquid chromatographymass spectrometry (LC-MS) analysis. The cytotoxic effect of these extracts on Saos-2 cell line and identification of their phenolic compounds have not been reported so far.

Methods: Cancer cell lines were provided from Department of Biological Sciences, Bursa University, Turkey. Different concentrations of the methanol, ethanol, and diluted water extracts $(0.5-5 \mathrm{mg} / \mathrm{mL})$ were tested on Saos-2 cell line. After 24, 48, and 72 hours, the cell viability was evaluated using 3-(4, 5-dimethylthiazol-2-yl)-2,5-diphenyltetrazolium bromide (MTT) method. For the investigation of total phenolic compounds of T. dasystyla and P. orientale Desf extracts LC-MS method was applied.

Results: According to the results diluted water extracts on the Saos-2 cancer cell line showed more cytotoxic effect than other solvents. The lowest $\mathrm{IC}_{50}$ value was $0.58 \pm 0.01 \mathrm{mg} / \mathrm{mL}$ within 72 hours belonged to $T$. dasystyla water extract.

Conclusions: Tilia dasystyla and Polygonatum orientale Desf extracts contain some polyphenolic compounds which showed cytotoxic effect on Saos-2 cancer cell line. The full potential of these herbal extracts is yet to be realized by further studies on animal models and subsequent trials.
\end{abstract}

Keywords: Anti-Cancer, LC-MS, Polygonatum orientale Desf, Saos-2, Tilia dasystyla

\section{Background}

Skeleton malignant tumor, defined as osteosarcoma, can metastasize to the other parts of the body, particularly lungs. Osteosarcoma, one of the most common malignant tumors, is more common in young age; this cancer is one of the most common types of cancer that occurs in mesenchymal bone marrow cells and affects the musculoskeletal system $(1,2)$. Prescription drugs suppress the immune system and have many side effects, for this reason, antioxidant compounds obtained from herbal extracts are preferred to prevent cancer or to support the treatment $(3,4)$.
Herbal medicine contains several antioxidant compounds, which neutralize free radicals and prevent lipid peroxidation. Plants are a rich source of antioxidant compounds that can protect cells from oxidative damages. Plants contain secondary metabolites, such as phenol and flavonoids, these compounds have antioxidant properties with strong potential for the clearance of free radicals in order to prevent diseases such as cancer (5, 6). Tilia is a genus in the Tiliaceae family with about 30 species of trees. These trees are found locally in Northern Hemisphere areas and known as a safe product as herbal medicine for symptoms of cold and anxiety. Tilia is used 
as anti-inflammatory, anti-diarrhea, anti-spasmodic, antihair loss, anti-anxiety, and sedative medications since it contains the wide range of bioactive compounds. Tilia bioactive compounds include hydrocarbons, esters, terpenes, quercetin, kaempferol, tannins and scopoletin, and other polyphenolic compounds $(7,8)$.

P. orientale Desf belongs to Asparagaceae family which grows in North of Iran. The rhizome of Polygonatum is used as an herbal medicine in traditional medicine. The anti-depressant, anti-inflammatory, anticancer, anti-fever, antioxidant, and antimicrobial activities of the Polygonatum rhizome have been shown in many studies $(9,10)$. Variety of compounds such as polysaccharides, saponins, phytohormones, glycosides, flavonoids, and alkaloids have been isolated from Polygonatum rhizome. Polysaccharides of Polygonatum have the most variety among the other compounds in these plants that have shown anti-cancer properties. Pharmacological studies on several species including P. odoratum, P. verticillatum, P. cyrtonema, and $P$. kingianum have been reported $(11,12)$.

\section{Objectives}

The purpose of this study was to investigate the cytotoxic effect of P. orientale Desf and T. dasystyla methanol, ethanol, and diluted water extracts on osteogenic sarcoma (Saos-2) cancer cell lines and identification of their phenolic compound by liquid chromatography-mass spectrometry (LC-MS) analysis. The LC-MS method is used to accurately identify phenolic compounds.

The cytotoxic effect of $T$. dasystyla and P. orientale Desf extracts on the Saos-2 cell line and identification of their phenolic compounds by the LC-MS method has not been reported until now.

\section{Methods}

\subsection{Material}

Methanol (99.9\%), ethanol (99.9\%), acetonitrile, and other LC-MS grade solvents were from Merck.

Dulbecco's Modified Eagle's medium/nutrient mixture F-12 (DMEM F12), fetal bovine serum (FBS), phosphatebuffered saline (PBS) , and 1\% Pen-Strep were from Gibco ${ }^{\circledR}$ and cell proliferation kit I were from Roche life science.

\subsection{Preparation of Plant Extracts}

$P$. orientale Desf and T. dasystyla species were purchased from Bagh Firuze, Tehran, Iran and were approved at Alzahra University Herbarium. In this study, the leaf of $T$. dasystyla and rhizome of $P$. orientale Desf were used for investigation.

Amount of $1 \mathrm{~g}$ of the dried plant was added in $100 \mathrm{ml}$ of $80 \%$ aqueous methanol, $80 \%$ aqueous ethanol, and diluted water solvents. The solvents were boiled in water bath for $60 \mathrm{~min}$ at temperature of $70^{\circ} \mathrm{C}$. Extracts were centrifuged for $20 \mathrm{~min}$ at $2000 \mathrm{rpm}$, supernatant was used in lyophilization process. Methanol, ethanol, and water solvents were completely removed by lyophilization process and powder of plants was dissolved in PBS to determine the cytotoxic effect of the extracts on the cancer cell line. For sterilization of solution, $0.22 \mathrm{~mm}$ filters were used and then solution was diluted with DMEM F12 culture medium to concentrations of $0.5-5 \mathrm{mg} / \mathrm{mL}$ (13).

\subsection{Cell Culture}

Osteogenic sarcoma (Saos-2) cell line was provided by Bursa University of Turkey. Cells were grown in DMEM-high glucose containing $10 \%$ FBS and $1 \%$ Pen-Strep incubated in $5 \% \mathrm{CO}_{2}$ humidified atmosphere and $37^{\circ} \mathrm{C}$ incubator (13).

3.4. 3-(4,5-Dimethylthiazol-2-yl)-2, 5-Diphenyltetrazolium Bromide (MTT) Assay

To determine the inhibition effect of extracts on the proliferation of cells, cell viability was detected by measuring MTT absorbance of viable cells. Eight-thousand cells for each well were seeded into 96-well plates for $24 \mathrm{~h}$, after $24 \mathrm{~h}$ cells were treated with various concentrations of extracts, and were incubated for $24 \mathrm{~h}, 48 \mathrm{~h}$, and $72 \mathrm{~h}$ in incubator. Subsequently, $10 \mathrm{~mL}$ of MTT $(5 \mathrm{mg} / \mathrm{mL})$ was added to each well and then cells were incubated for 4 hours. Then $100 \mathrm{~mL}$ of solubilization buffer was added to the wells and plates were kept in incubator for overnight, and then absorbance was measured at a wavelength of $570 \mathrm{~nm}$ using a microplate reader (Cytation ${ }^{\mathrm{TM}}$ Biotek, USA).

The percentage of cell viability was calculated using the formula:

(Mean OD treated well $) \div($ mean OD control well $) \times$ $100=\%$

$\mathrm{IC}_{50}$ was calculated by drawing curve using different concentrations of extract and cell viability percentage (14).

\subsection{LC-ESI/MS Analysis}

\subsubsection{Extraction of Phenolic Compounds}

The extracts were prepared with methanol solvent. Amount of $0.5 \mathrm{~g}$ of the dry sample added to $10 \mathrm{~mL}$ of $80 \%$ aqueous methanol solvent. The mixtures were heated for $60 \mathrm{~min}$ in water bath at $70^{\circ} \mathrm{C}$. Then, the mixtures were centrifuged at $2000 \mathrm{rpm}$ for $20 \mathrm{~min}$ at $25^{\circ} \mathrm{C}$. The supernatants 
were filtered through a $22 \mu \mathrm{m}$ filter then was used for the identification of total phenolic contents by LC-ESI/MS analysis.

Phenolic compounds in the $80 \%$ aqueous methanol extracts of $T$. dasystyla and P. orintale Desf were analyzed by the LCMS-8040 system (Shimadzu, Kyoto, Japan). The mobile phase consisted of $100 \%$ methanol (solvent A) and acetonitrile (solvent $B)(1: 1 \mathrm{v} / \mathrm{v})$. The mobile phase flow rate was $0.3 \mathrm{~mL} / \mathrm{min}$. The column temperature was fixed at $40^{\circ} \mathrm{C}$. Phenolic compounds were detected by a full scan mode ranged m/z 100 - 1000 amu. MS detection was applied using Shimadzu LCMS 8040 model triple quadrupole mass spectrometer equipped with an ESI source operating in both positive and negative ionization modes. Data were acquired by Lab Solutions software (15).

\subsection{Statistical Analysis}

Statistical analysis was performed using the ANOVA test by SPSS version 24 program and the P Value $<0.05$ was considered significant. Data were expressed as means \pm standard deviation.

\section{Results}

Cytotoxic effect of the various concentrations of $T$. dasystyla and P. orientale Desf extracts on the Saos-2 cell line are given in Figures 1 and 2. Cytotoxic effect of three different solvent extracts (water, methanol, and ethanol) from $0.5 \mathrm{mg} / \mathrm{mL}$ to $5 \mathrm{mg} / \mathrm{mL}$ concentrations on Saos-2 cell line was tested by MTT assay. Cell viability was determined after treatment within different intervals of 24,48 , and 72 hours. Extracts reduced the cell proliferation in a dose and time-dependent manner. Among different solvents, water showed higher cytotoxicity to cancer cells. The most cytotoxic effect of water extract was at the concentration of 5 $\mathrm{mg} / \mathrm{mL}$ at $72 \mathrm{~h}$.

The maximum cell growth inhibition of the Saos- 2 cell line was at 72 hours and at a concentration $5 \mathrm{mg} / \mathrm{mL}$ of $T$. dasystyla and $P$. orientale Desf water extractswith $14 \%$ and $29 \%$ of cell viability, respectively. According to Figure 3 , the lowest values of $\mathrm{IC}_{50}$ was $0.58 \pm 0.01 \mathrm{mg} / \mathrm{mL}$ belonged to $T$. dasystyla water extract. The lowest $\mathrm{IC}_{50}$ value of $P$. orientale Desf was $2.9 \pm 0.01 \mathrm{mg} / \mathrm{mL}$ belonged to water extract. T. dasystyla showed more cytotoxic effect than P. orientale Desf and the water solvent was the most efficient in extracting antioxidants among the other solvents. The most effective solvents with anticancer properties were water, methanol, and ethanol extracts, respectively. Data statistical analysis (Pvalue $<0.05$ ) of Figures 1 and 2 indicated that

\begin{tabular}{|c|c|}
\hline T. dasystyla Compound & P. orientale Desf Compound \\
\hline 5,6-dihydroxy-30 & Quercetin-7-O-galloyl-glucoside \\
\hline 40,7-trimethoxyflavone & Corilagin derivative \\
\hline Quercetin-7-O-galloyl-glucoside & $\begin{array}{l}\text { Naringenin-40-methoxy-7- } \\
\text { pyranoside }\end{array}$ \\
\hline Corilagin derivative & Gallagic acid dilactone \\
\hline Quercetin-7-b-O-diglucoside & Methyl-(S)-flavogallonate \\
\hline $\begin{array}{l}\text { Naringenin-40-methoxy-7- } \\
\text { pyranoside }\end{array}$ & Oleanane type triterpenoid \\
\hline Gallagic acid dilactone & Unknown Ellagitannin \\
\hline Methyl-(S)-flavogallonate & Malic acid \\
\hline $\begin{array}{l}\text { trans-resveratrol-3-O-b-galloyl- } \\
\text { glucoside }\end{array}$ & Chlorogenic acid \\
\hline $\begin{array}{l}\text { cis-resveratrol-3-O-b-galloyl- } \\
\text { glucoside }\end{array}$ & Caffeic acid \\
\hline Oleanane-type triterpenoid & Ferulic acid hexoside \\
\hline Malic acid & Caffeoylquinic acid derivative \\
\hline Aconitic acid & Caffeic acid derivative \\
\hline Chlorogenic acid & Myricetin rhamnoside \\
\hline Protocatechuic acid & Naringenin pentose \\
\hline Hyperoside & Sinapic acid hexose \\
\hline dicaffeoylquinic acid & Prunetin \\
\hline \multicolumn{2}{|l|}{ caffeoylquinic acid derivative } \\
\hline \multicolumn{2}{|l|}{ Caffeic acid derivative } \\
\hline \multicolumn{2}{|l|}{ Procyanidin dimer (type B1 or B2) } \\
\hline \multicolumn{2}{|l|}{ (epi)catechin-(epi)gallocatechin } \\
\hline \multicolumn{2}{|l|}{ Procyanidin trimer } \\
\hline \multicolumn{2}{|l|}{ Catechin, Myricetin rhamnoside } \\
\hline Sinapic acid hexose & \\
\hline
\end{tabular}

there was a significant difference between all solvents in $T$. dasystyla extracts and there was a significant difference between ethanol solvent with water and methanol solvents in P. orientale Desf extracts.

Table 1 shows the phenolic compounds identified by LC-ESI-MS. The most abundant phenolic compounds in P. orientale Desf were chlorogenic acid, naringenin, and prunetin, respectively and the most abundant phenolic compounds in T. dasystyla were dicaffeoylquinic acid, procyanidin dimer (type B1 or B2), and chlorogenic acid. Simple and gradient elution-based ESI-LC/MS method was applied for the analysis of the phenolic compounds.

A solvent system consisting of methanol and acetonitrile was successful in the separation of phenolic compounds in the plant extracts with good resolution. 


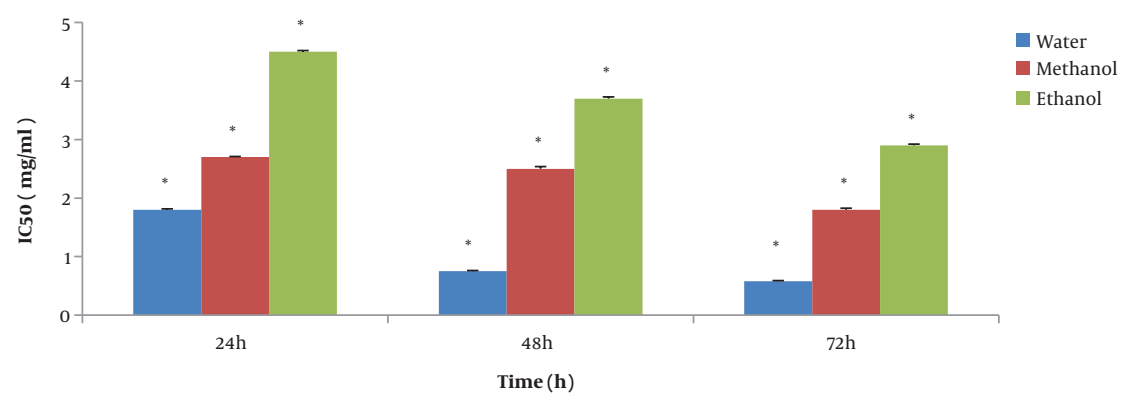

Figure 1. IC 50 values of different T. dasystyla extracts on the Saos-2 cancer cell for 24,48 , and $72 \mathrm{~h}$. Experiments are performed in triplicate and express as the mean standard deviation. Values in each column marked with * show significant differences between solvent (water, methanol, and ethanol) in each time $(\mathrm{P}<0.05)$.

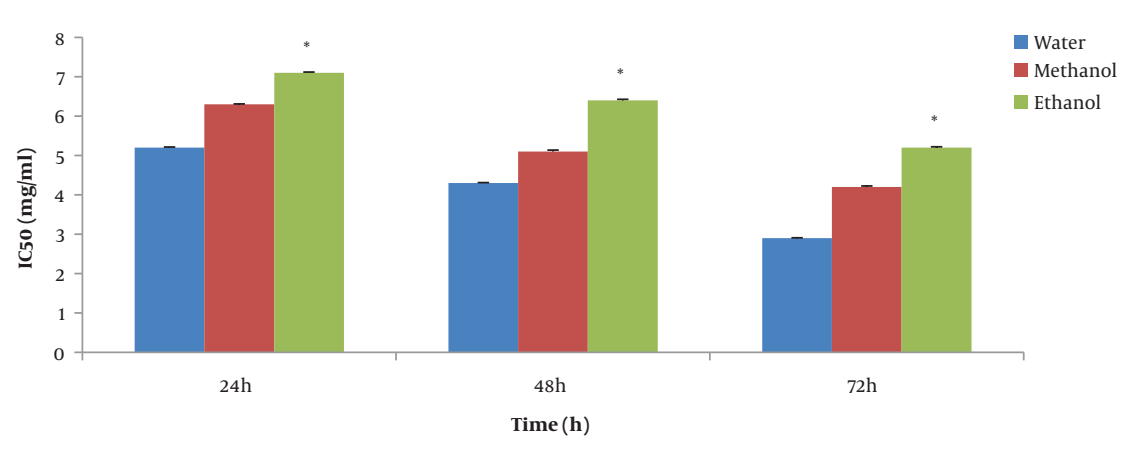

Figure 2. $\mathrm{IC}_{50}$ values of the different $P$. orientale Desf extracts (water, methanol, and ethanol) on the Saos-2 cancer cell for 24,48 , and $72 \mathrm{~h}$. Experiments are performed in triplicate and express as the mean standard deviation. Values in each column marked with * show significant differences between solvent (water, methanol, and ethanol) in each time $(\mathrm{P}<0.05)$.

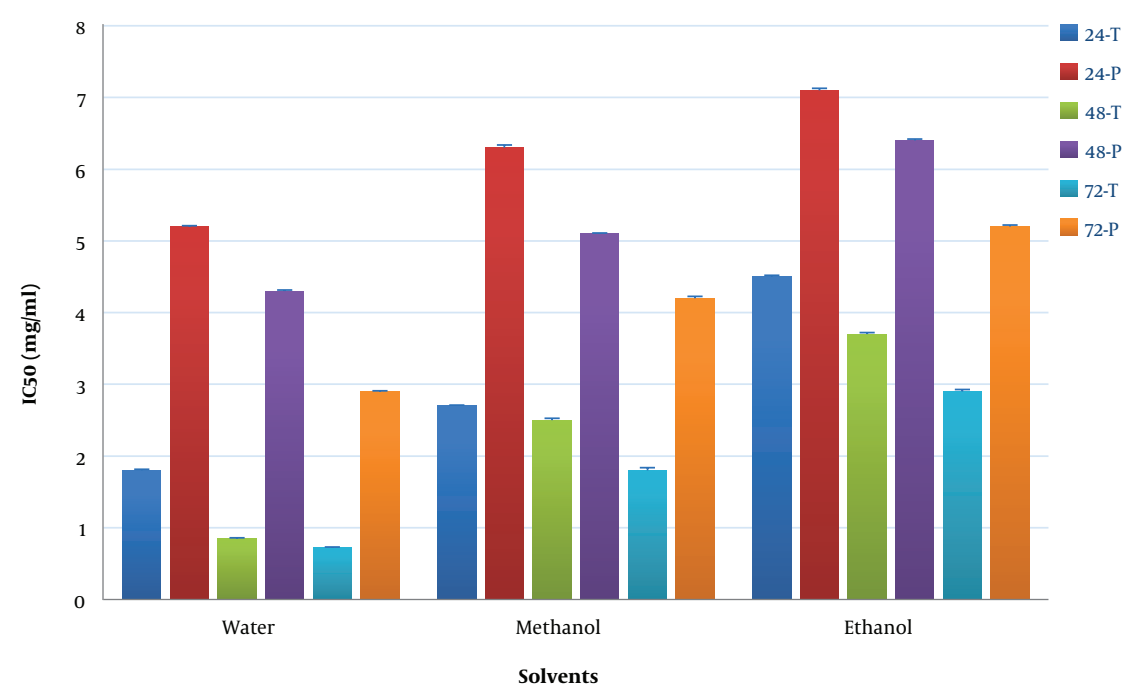

Figure 3. Comparison of the $\mathrm{IC}_{50}$ values of the $T$. dasystyla $(\mathrm{T})$ and $P$. orientale Desf (P) different extracts (water, methanol, and ethanol) on the Saos-2 cancer cell for 24,48 , and $72 \mathrm{~h}$. Experiments are performed in triplicate and express as the mean standard deviation.

Results of identification and fragments are shown in Figures 4 and 5 .

\section{Discussion}

Cytotoxic effect of various concentrations of T. dasystyla and $P$. orientale Desf extracts using three different solvents 
A

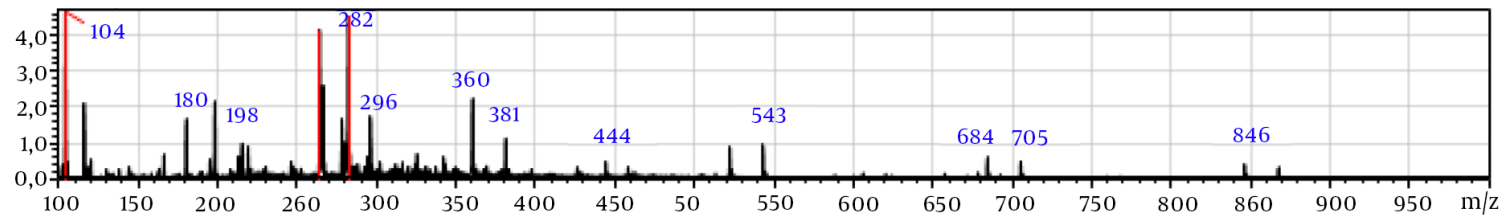

B

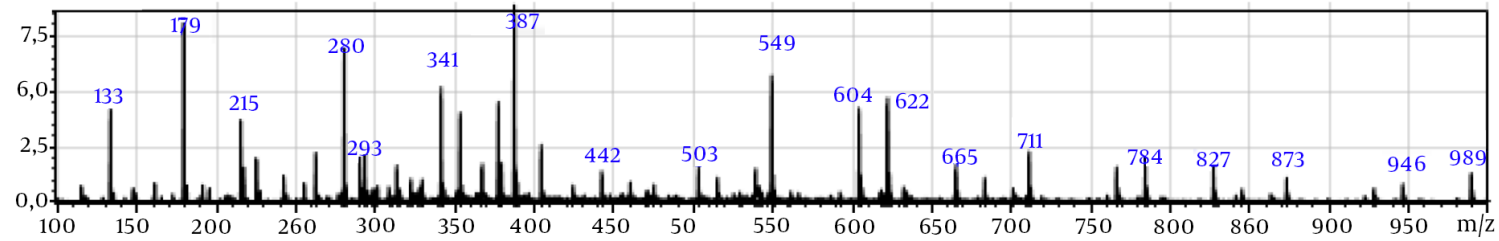

C

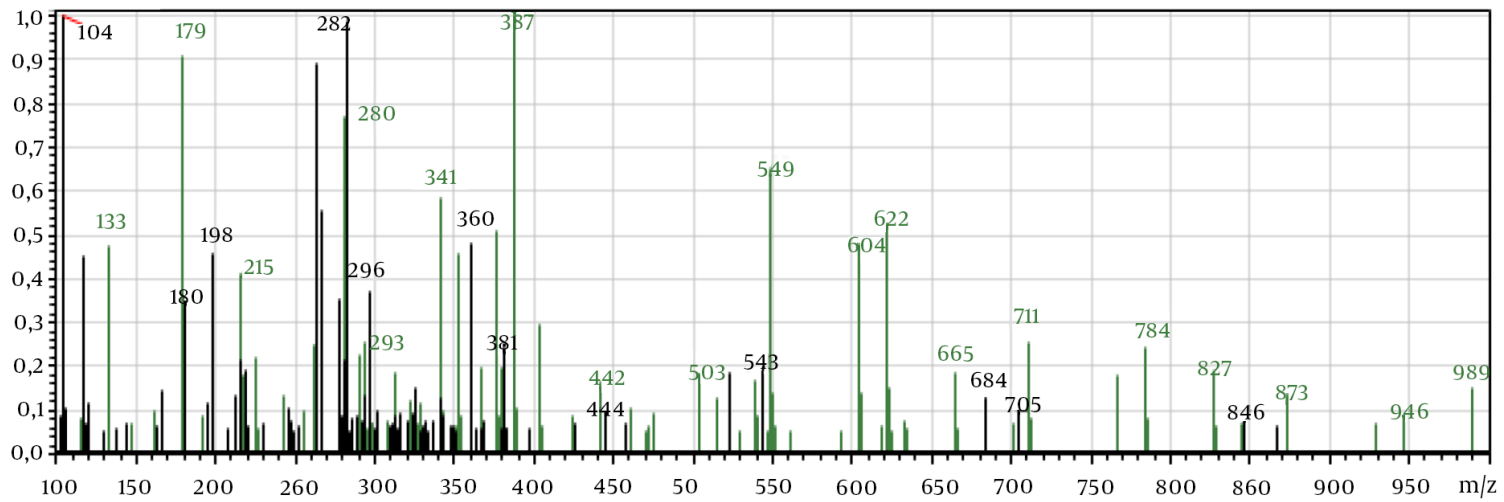

Figure 4. LC-ESI/MS analysis ion mass spectra of P. orientale Desf. A, positive ionization; B, negative ionization; C, total spectrum.

including water, methanol, and ethanol. According to the data statistical analysis (P value $<0.05$ ) of data in Figures 1 and 2, water was the most efficient solvent in the extracting antioxidants, since water extract showed more cytotoxic effect on Saos-2 cancer cell line, after water, methanol was more efficient solvent among others. Also extracts showed time- dose depended manner in cytotoxic effect on Saos-2 cells. According to the data of Figure 3, the maximum inhibition of cancer cells growth was at 72 hours and at a concentration of $5 \mathrm{mg} / \mathrm{mL}$ of $T$. dasystyla water extract with the percentage of $86 \%$ cell growth inhibition.

Secondary metabolites in plants, such as phenols and flavonoids, are antioxidant compounds which have strong potential for cancer treatment and prevention (5). The yield of extraction depends on the solvents with varieties of polarity. The extraction yield increases with increasing polarity of the solvent used in extraction. Therefore, the most effective solvents in the extraction of phenolic compounds were water, methanol and ethanol, respectively (16). The temperature of the extraction method is also important. The amount of phenolic compounds start to increase at $60^{\circ} \mathrm{C}$. At this temperature, heavy polyphenols decompose to a variety of phenolic compounds with lower molecular weight. Also, the solubility of phenolic compounds increases in this temperature. So in this study, the water bath method was used due to the applied temperature within the process of extraction (17).

Phenolic compounds identification of T. dasystyla and P. orientale Desf were performed by LC-MS analysis for the first time in this study. But phenolic compounds of other species of Tilia and Polygonatum have been identified in other studies. 
A

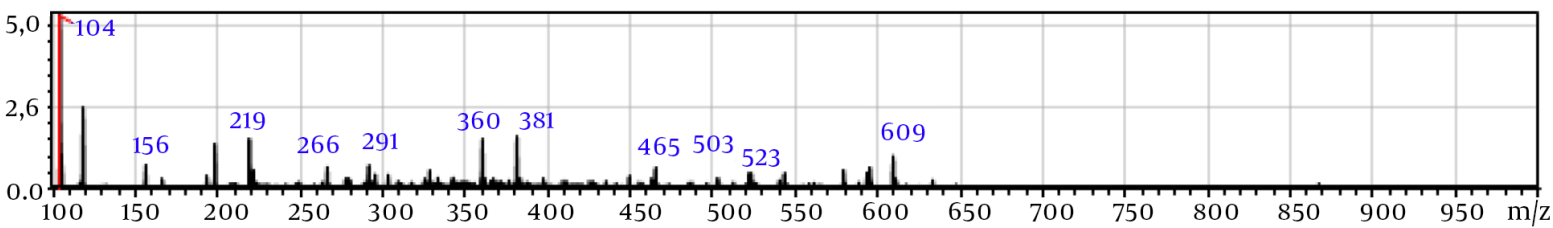

B

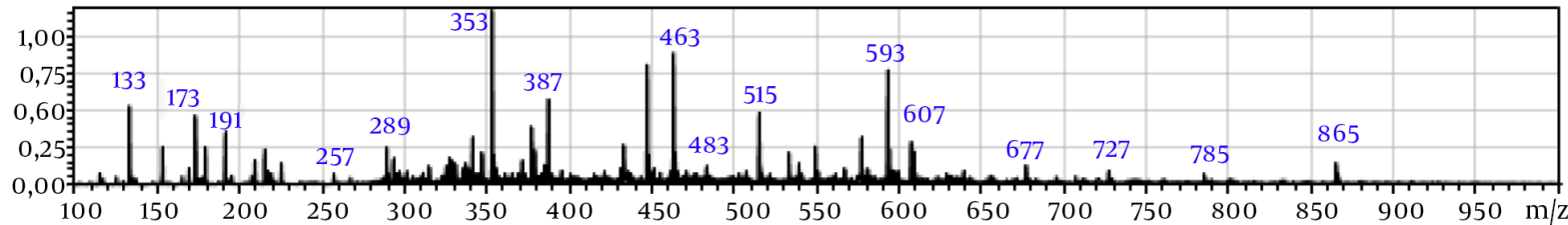

C

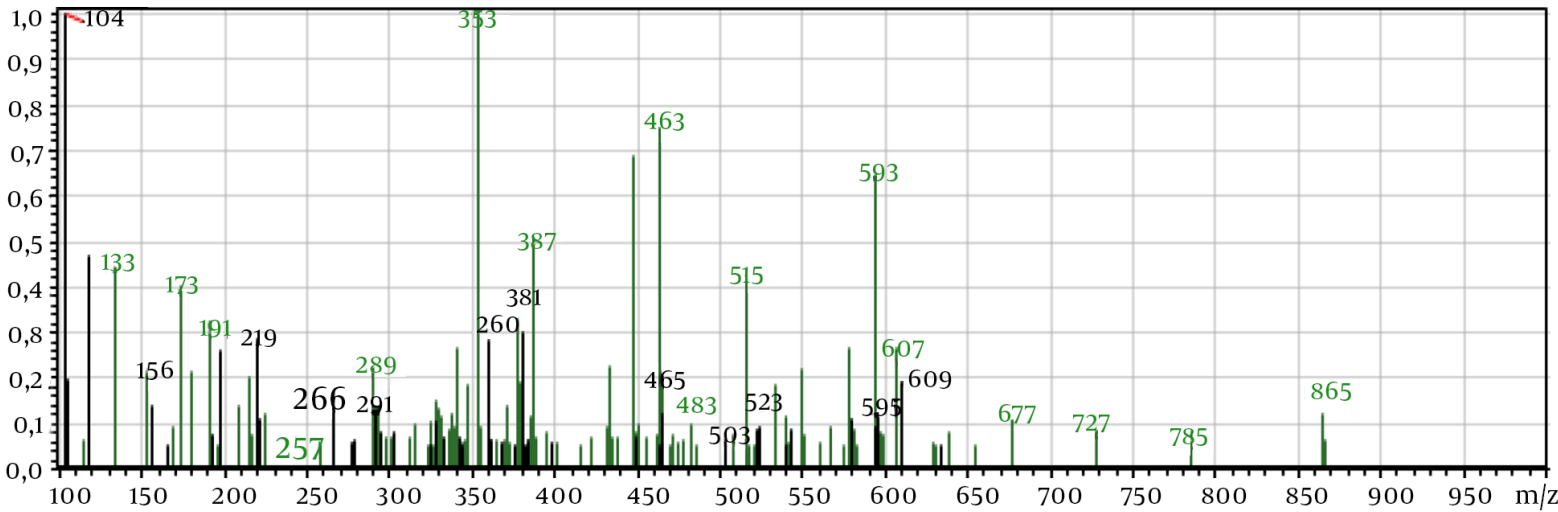

Figure 5. LC-ESI/MS analysis ion mass spectra of T. dasystyla. A, Positive ionization; B, negative ionization; C, total spectrum.

Catechin, naringenin, quercetin, protocatechuic, pcoumaric, chlorogenic, ferulic, and caffeic acids were determined in all Tilia argentea extracts and protocatechuic, ferulic, coumaric, gallic acids, naringenin and cholorogenic acid were identified in Polygonum bistorta extracts (15).

The cytotoxic effects of $T$. dasystyla and P. orientale Desf extracts on cancer cell lines have not been reported so far. However, some studies have reported the anticancer properties of other Tilia and Polygonatum species.

The structure of specific homoisoflavone has been identified from Polygonatum odoratum root which induces Bcl-2 phosphorylation and causes apoptosis in breast cancer cells (18). Polygonatum cyrtonema lectin (PCL) also showed anti-proliferative and apoptosis-inducing activi- ties. This component showed cytotoxic effect on murine fibrosarcoma L929 and melanoma A375 cancer cells by interrupting of a mitochondria-mediated ROS-p38-p53 pathway and this caused the growth inhibition of cancer cell lines $(19,20)$. P. odoratum extracts showed growth inhibition properties on human breast cancer MDA-MB-231 cells and induced apoptosis (9).

The extracts of Tilia cordata Mill flowers showed antiproliferative activities on BW 5147 lymphoma tumor cells and T. americana var. mexicana had antitumor activities on K-562 leukemia cell line (21, 22). Extract from trunk of Tilia amurensis Rupr. (Tiliaceae) had cytotoxic effect on A549, SKOV-3, SK-MEL-2, and HCT-15 cell lines and the Tilia $\times$ viridis extracts showed anti-proliferative properties on murine lymphocytes cancer cells $(23,24)$. 


\subsection{Conclusions}

Based on the results, the extracts of $T$. dasystyla and $P$. orientale Desf contained polyphenolic compounds which never been isolated before from these species. Cytotoxic effect of extracts on Saos- 2 cancer cell line may be due to the presence of antioxidant compounds such as phenol and flavonoids. In addition, the results showed water solvent is more efficient in extracting of antioxidants. T. dasystyla contained more polyphenolic compounds than $P$. orientale Desf and this could be one of the reasons for the anticancer properties of $T$. daystyla. This study requires more detailed investigation in future studies. Isolation and purification of the polyphenolic compounds in these plants and their anti-cancer effect on different cell lines and finally how to use them in the pharmaceutical and health industries in future studies can be investigated.

\section{Acknowledgments}

Not declared.

\section{Footnotes}

Authors' Contribution: Study concept and design: Ertuğrul Kaya, Parichehr Hanachi, and Roshanak Zarringhalami. Acquisition of data: Roshanak Zarringhalami, Aydan Fulden Ağan, Mert Donmez, and Kağan Ağan. Analysis and interpretation of data: Roshanak Zarringhalami, Aydan Fulden Ağan, Mert Donmez, and Kağan Ağan. Drafting of the manuscript: Roshanak Zarringhalami and Parichehr Hanachi. Critical revision of the manuscript for important intellectual content: Ertuğrul Kaya, Parichehr Hanachi, and Roshanak Zarringhalami. Statistical analysis: Roshanak Zarringhalami, Mert Donmez. Administrative, technical, and material support: Ertuğrul Kaya, Parichehr Hanachi, and Kağan Ağan. Study supervision: Ertuğrul Kaya and Parichehr Hanachi,

Conflict of Interests: The authors declare no conflict of interests.

Ethical Approval: The experiment was performed under the approval of Motamed Cancer Institute-Academic Center for Education, Culture and Research, Tehran, Iran (approval ID: IR.ACECR.REC.1398.006).

Funding/Support: The study was supported by Duzce University, Turkey and Alzahra University, Iran.

\section{References}

1. Riggs BL, Melton L3. The prevention and treatment of osteoporosis. N Engl J Med. 1992;327(9):620-7. doi: 10.1056/NEJM199208273270908. [PubMed: 1640955].

2. Picci P. Osteosarcoma (osteogenic sarcoma). Orphanet J Rare Dis. 2007;2:6. doi: 10.1186/1750-1172-2-6. [PubMed: 17244349]. [PubMed Central: PMC1794406].

3. Richardson MA, Sanders T, Palmer JL, Greisinger A, Singletary SE. Complementary/alternative medicine use in a comprehensive cancer center and the implications for oncology. J Clin Oncol. 2000;18(13):250514. doi: 10.1200/JCO.2000.18.13.2505. [PubMed:10893280].

4. Ho JW, Leung YK, Chan CP. Herbal medicine in the treatment of cancer. Curr Med Chem Anticancer Agents. 2002;2(2):209-14. doi: 10.2174/1568011023354164. [PubMed: 12678744].

5. Rao YK, Geethangili M, Fang SH, Tzeng YM. Antioxidant and cytotoxic activities of naturally occurring phenolic and related compounds: A comparative study. Food Chem Toxicol. 2007;45(9):1770-6. doi: 10.1016/j.fct.2007.03.012. [PubMed:17475387].

6. Treasure J. Herbal medicine and cancer: An introductory overview. Semin Oncol Nurs. 2005;21(3):177-83. doi: 10.1016/j.soncn.2005.04.006. [PubMed: 16092805].

7. Kosakowska OK, Baczek K, Przybył JL, Ejdys M, Kuźma P, Obiedziński $\mathrm{M}$, et al. Intraspecific variability in the content of phenolic compounds, essential oil and mucilage of small-leaved lime (Tilia cordata Mill.) from Poland. Ind Crops Prod. 2015;78:58-65. doi: 10.1016/j.indcrop.2015.10.002.

8. Delnavazi MR, Shahabi M, Yassa N. Flavonoids from the leaves of Iranian Linden; Tilia rubra subsp. caucasica. Res J Pharmacogn. 2015;2(3):17-22.

9. Tai Y, Sun YM, Zou X, Pan Q, Lan YD, Huo Q, et al. Effect of Polygonatum odoratum extract on human breast cancer MDA-MB-231 cell proliferation and apoptosis. Exp Ther Med. 2016;12(4):2681-7. doi: 10.3892/etm.2016.3630. [PubMed: 27698772]. [PubMed Central: PMC5038215].

10. Khan H, Saeed M, Gilani AH, Muhammad N, Haq IU, Ashraf N, et al. Antipyretic and anticonvulsant activity of Polygonatum verticillatum: Comparison of rhizomes and aerial parts. Phytother Res. 2013;27(3):468-71. doi: 10.1002/ptr.4721. [PubMed: 22610947].

11. Wujisguleng W, Liu $\mathrm{Y}$, Long $\mathrm{C}$. Ethnobotanical review of food uses of Polygonatum (Convallariaceae) in China. Acta Soc Bot Pol. 2012;81(4):239-44. doi: 10.5586/asbp.2012.045.

12. Bai $\mathrm{H}, \mathrm{Li}$ W, Zhao $\mathrm{H}$, Anzai Y, Li H, Guo $\mathrm{H}$, et al. Isolation and structural elucidation of novel cholestane glycosides and spirostane saponins from Polygonatum odoratum. Steroids. 2014;80:7-14. doi: 10.1016/j.steroids.2013.11.013. [PubMed: 24291419].

13. Ko SG, Kim HP, Jin DH, Bae HS, Kim SH, Park CH, et al. Saussurea lappa induces G2-growth arrest and apoptosis in AGS gastric cancer cells. Cancer Lett. 2005;220(1):11-9. doi: 10.1016/j.canlet.2004.06.026. [PubMed: 15737683].

14. Vijayarathna S, Sasidharan S. Cytotoxicity of methanol extracts of Elaeis guineensis on MCF-7 and Vero cell lines. Asian Pac J Trop Biomed. 2012;2(10):826-9. doi: 10.1016/S2221-1691(12)60237-8. [PubMed: 23569855]. [PubMed Central: PMC3609226].

15. Demiray S, Pintado ME, Castro PML. Evaluation of phenolic profiles and antioxidant activities of Turkish medicinal plants: Tilia argentea, Crataegi folium leaves and Polygonum bistorta roots. World Acad Sci Eng Technol. 2009;54:312-7.

16. Do QD, Angkawijaya AE, Tran-Nguyen PL, Huynh LH, Soetaredjo FE, Ismadji S, et al. Effect of extraction solvent on total phenol content, total flavonoid content, and antioxidant activity of Limnophila aromatica. J Food Drug Anal. 2014;22(3):296-302. doi: 10.1016/j.jfda.2013.11.001. [PubMed: 28911418]. 
17. Spigno G, De Faveri DM. Antioxidants from grape stalks and marc: Influence of extraction procedure on yield, purity and antioxidant power of the extracts. J Food Eng. 2007;78(3):793-801. doi: 10.1016/j.jfoodeng.2005.11.020.

18. Rafi MM, Vastano BC. Identification of a structure specific Bcl-2 phosphorylating homoisoflavone molecule from Vietnamese coriander (Polygonatum odoratum) that induces apoptosis and G2/M cell cycle arrest in breast cancer cell lines. Food Chemistry. 2007;104(1):332-40. doi: 10.1016/j.foodchem.2006.11.045.

19. Liu B, Wu JM, Li J, Liu JJ, Li WW, Li CY, et al. Polygonatum cyrtonema lectin induces murine fibrosarcoma L929 cell apoptosis and autophagy via blocking Ras-Raf and PI3K-Akt signaling pathways. Biochimie. 2010;92(12):1934-8. doi: 10.1016/j.biochi.2010.08.009. [PubMed: 20713122].

20. Liu B, Cheng Y, Zhang B, Bian HJ, Bao JK. Polygonatum cyrtonema lectin induces apoptosis and autophagy in human melanoma A375 cells through a mitochondria-mediated ROS-p38-p53 pathway. Cancer Lett. 2009;275(1):54-60. doi: 10.1016/j.canlet.2008.09.042. [PubMed:
19010591].

21. Barreiro Arcos ML, Cremaschi G, Werner S, Coussio J, Ferraro G, Anesini C. Tilia cordata Mill. Extracts and scopoletin (isolated compound): differential cell growth effects on lymphocytes. Phytother Res. 2006;20(1):34-40. doi:10.1002/ptr.1798. [PubMed: 16397918].

22. Carmona-Aparicio L, Ortega-Cuellar D, Gonzalez-Trujano ME Rodriguez-Chavez JL, Aguirre-Hernández E, Sampieri AIII, et al. Ethyl acetate extract of Tilia americana var. mexicana, a new citotoxicity and antioxidant agent. J Food Agric Environ. 2014;12(2):78-81.

23. Kim KH, Moon E, Kim SY, Choi SU, Lee KR. Lignan constituents of Tilia amurensis and their biological evaluation on antitumor and antiinflammatory activities. Food Chem Toxicol. 2012;50(10):3680-6. doi: 10.1016/j.fct.2012.07.014. [PubMed: 22819933].

24. Manuele MG, Ferraro G, Anesini C. Effect of Tilia x viridis flower extract on the proliferation of a lymphoma cell line and on normal murine lymphocytes: Contribution of monoterpenes, especially limonene. Phytother Res. 2008;22(11):1520-6. doi: 10.1002/ptr.2524. [PubMed: 18688792]. 